\title{
Quantification of whey proteins by reversed phase-HPLC and effectiveness of mid-infrared spectroscopy for their rapid prediction in sweet whey
}

\author{
Alba Sturaro, Massimo De Marchi, ${ }^{1}$ Antonio Masi, and Martino Cassandro \\ Department of Agronomy, Food, Natural Resources, Animals, and Environment (DAFNAE), University of Padova, Viale dell'Università 16, \\ 35020 Legnaro (PD), Italy
}

\begin{abstract}
In the dairy industry, membrane filtration is used to reduce the amount of whey waste and, simultaneously, to recover whey proteins (WP). The composition of WP can strongly affect the filtration treatment of whey, and rapid determination of WP fractions would be of interest for dairy producers to monitor WP recovery. This study aimed to develop mid-infrared spectroscopy (MIRS) prediction models for the rapid quantification of protein in sweet whey, using a validated rapid reversed phase (RP)-HPLC as a reference method. Quantified WP included $\alpha$-lactalbumin $(\alpha-$ LA), $\beta$-lactoglobulin ( $\beta$-LG) A and B, bovine serum albumin, caseinomacropeptides, and proteose peptone. Validation of RP-HPLC was performed by calculating the relative standard deviation (RSD) in repeatability and reproducibility tests for WP retention time and peak areas. Samples of liquid whey $(n=187)$ were analyzed by RP-HPLC and scanned through MIRS to collect spectral information (900 to $4,000 \mathrm{~cm}^{-1}$ ); statistical analysis was carried out through partial least squares regression and random cross-validation procedure. Retention times in RP-HPLC method were stable (RSD between 0.03 and $0.80 \%$ ), whereas the RSD of peak area (from 0.25 to $8.48 \%$ ) was affected by WP relative abundance. Higher coefficients of determination in validation for MIRS model were obtained for protein fractions present in whey in large amounts, such as $\beta$-LG (0.58), total identified WP (0.58), and $\alpha$-LA (0.56). Results of this study suggest that MIRS is an easy method for rapid quantification of detail protein in sweet whey, even if better resolution was achieved with the method based on RP-HPLC. The prediction of WP in sweet whey by MIRS might be used for screening and for classifying sweet whey according to its total and individual WP contents.
\end{abstract}

Received November 6, 2014.

Accepted September 15, 2015.

${ }^{1}$ Corresponding author: massimo.demarchi@unipd.it
Key words: whey protein quantification, mid-infrared spectroscopy, reversed phase (RP)-HPLC

\section{INTRODUCTION}

The increasing consumer demand for products with healthy and high nutritional properties has led the dairy industry to recognize the value of whey proteins (WP; Smithers, 2008). Whey proteins can be incorporated in several food products to maintain the functional and nutritional value (Lo and Bastian, 1998). Recently, dairy producers have exploited different processes for whey treatments to recycle WP (Prazeres et al., 2012). Ultrafiltration of whey is one of the most important applications to recover WP and produce WP concentrate (WPC; Singer et al., 1990). The main WP involved are $\beta-\mathrm{LG}\left(\beta-\mathrm{LG}_{\mathrm{A}}\right.$ and $\left.\beta-\mathrm{LG}_{\mathrm{B}}\right)$ and $\alpha$-LA; other minor WP are BSA, various peptides such as caseinomacropeptide (CMP) formed by chymosin cleavage of $\kappa$-casein, and proteose peptone $(\mathbf{P P})$ resulting from proteolysis of $\beta$-casein by indigenous milk proteinases. The WP composition can strongly affect the UF treatment (Guyomarc'h et al., 2009). Indeed, different chromatographic methods were designed for the WP characterization, such as ion-exchange chromatography (Doultani et al., 2004), size exclusion (Dissanayake and Vasiljevic, 2009; Torres et al., 2011), and reversed phase (RP)-HPLC (Anandharamakrishnan et al., 2008; Innocente et al., 2011). The aforementioned chromatographic methods are not applicable in the dairy industry because they are time consuming (e.g., at least $20 \mathrm{~min}$ per sample). An important need of the dairy industry is the rapid characterization of WP destined for UF. Mid-infrared spectroscopy (MIRS) combined with chemometric analysis has been recently proposed as fast, nondestructive, and cheap technique to predict several chemical and technological traits of milk (De Marchi et al., 2014). The implementation of MIRS in the dairy industry should be of interest not only for milk but also for whey products, because rapid and cheap assessment of quality whey produced after the cheese making is needed. 
Interest in the valorization of whey components is related to the improvement of economic revenue for the dairy industry. Indeed, the recovery and concentration of WP provides new ingredients that are widely used in food and nonfood sectors. The rapid and easy prediction of WP fractions by MIRS should be of interest for dairy industry; moreover, to our knowledge, no studies have been performed so far to evaluate the effectiveness of MIRS to predict WP fractions in whey.

The aims of this study were (1) to develop a rapid and high-resolution RP-HPLC method for individual WP quantification, and (2) to evaluate the potential of MIRS for the prediction of proteins in sweet whey.

\section{MATERIALS AND METHODS}

\section{Reagents and Samples Collection}

Guanidine hydrochloride (GdnHCl), Bis-Tris buffer, sodium citrate, DL-dithiothreitol, trifluoroacetic acid (TFA), acetonitrile (ACN), and standard purified proteins $\left(\alpha-\mathrm{LA}, \beta-\mathrm{LG}_{\mathrm{A}}, \beta-\mathrm{LG}_{\mathrm{B}}\right.$, and $\left.\mathrm{BSA}\right)$ were purchased from Sigma (Sigma-Aldrich, St. Louis, MO). Pure water was obtained from a Milli-Q plus $(<18.3$ $\mathrm{M} \Omega \cdot \mathrm{cm}$; Millipore, Billerica, MA) system in our laboratory.

Sweet whey from pasteurized milk was collected from a dairy plant without any preservative (Soligo, Treviso, Italy); A total of 187 whey samples were collected from May to August 2014 and analyzed by both RP-HPLC and MIRS.

\section{Chromatographic Conditions and Repeatability and Reproducibility Tests for RP-HPLC Method}

Whey protein fractions were quantified by a rapid RP-HPLC method. The method was used as the reference method for analysis of WP in whey and whey-derived products (e.g., WPC) after filtration. The chromatographic system used was an Agilent 1260 Series (Agilent Technologies, Santa Clara, CA) equipped with a quaternary pump, a diode array detector, and an auto-sampler with an injection loop of $100 \mu \mathrm{L}$. Calibration of the chromatographic system was carried out using standard protein solutions and analyzed in duplicate. Standard protein solutions were prepared with the following purified protein powders: $\alpha-\mathrm{LA}, \beta-\mathrm{LG}_{\mathrm{A}}$ and $\beta-\mathrm{LG}_{\mathrm{B}}$, and BSA (Sigma-Aldrich). Caseinomacropeptide and PP were purified from bulk bovine milk as proposed by Mollè et al. (2006) and Paquet et al. (1988), respectively. Spectrophotometric Bradford assay was used for CMP and PP quantification at $595 \mathrm{~nm}$ following the manufacturer's instruction (Sigma-Aldrich). Known concentrations of standard protein solutions were prepared in $6 \mathrm{M} \mathrm{GdnHCl}$, as described by Bobe et al. (1998), and injected in the chromatographic system. Retention time was registered for each pure protein and used for protein identification in whey samples. Calibration curves for each protein were obtained by regression of the peak area and injected concentration.

The HPLC equipment was controlled by the Agilent Chem-Station for LC Systems software (Agilent Technologies), which sets solvent gradient, data acquisition, and data processing. Separations were performed on a reversed-phase analytical column C8 (Zorbax 300SBC8 RP; Agilent Technologies) with Poroshell packing $(5 \mu \mathrm{m}, 300 \AA, 2.1 \times 75 \mathrm{~mm})$.

The gradient elution was carried out with a mixture of 2 solutions, A and B. Solution A consisted of $0.1 \%$ TFA and 5.0\% ACN in water, and solution B was $0.1 \%$ TFA in ACN. The gradient started with $5.0 \%$ solution $\mathrm{B}$; after $30 \mathrm{~s}$, the gradient was $15.0 \% \mathrm{~B}$, and at $1 \mathrm{~min}$, it was $18.0 \%$ B. Afterward, the gradient was from 18.0 to $27.5 \%$ in $1 \mathrm{~min}$, from 27.5 to $30.5 \%$ in $1 \mathrm{~min}$, from 30.5 to $31.0 \%$ in $15 \mathrm{~s}$, from 31.0 to $32.0 \%$ in $45 \mathrm{~s}$, from 32.0 to $33.8 \%$ in $35 \mathrm{~s}$, and from 33.8 to $50.0 \%$ in $1.10 \mathrm{~min}$. From 5.45 to $7 \mathrm{~min}$ (end of the run), the gradient was brought back to initial conditions $(5.0 \%$ B). Between sample injections, the column was re-equilibrated under the starting conditions for $2 \mathrm{~min}$. The total analysis time per sample was $9.0 \mathrm{~min}$. The flow rate was 2.5 $\mathrm{mL} / \mathrm{min}$, the column temperature was kept at $70^{\circ} \mathrm{C}$, and the detection was at a wavelength of $214 \mathrm{~nm}$. The injection volume consisted of $2 \mu \mathrm{L}$. To improve precision of the method, a precolumn was used, as proposed by Bonfatti et al. (2008), and a blank (6 M GdnHCl) was run before sample injection. The cleaning run was an isocratic elution of $50 \%$ solvent B.

Ten samples of whey were used for the evaluation of chromatographic method: repeatability and reproducibility tests were performed as proposed by Bonfatti et al. (2008) over $4 \mathrm{~d}$ of analysis. Data were expressed as relative standard deviation (RSD) for WP peak areas and retention time within and across days.

\section{Spectral Collection and Chemometric Analysis}

Whey spectra were recorded by MilkoScan FT2 (Foss, Hillerød, Denmark), within $4 \mathrm{~h}$ of whey collection, in a spectrum range from 900 to $4,000 \mathrm{~cm}^{-1}$, for a total of 1,060 absorbance data points. Whey samples were stored at standard temperature $\left(25^{\circ} \mathrm{C}\right)$ until MilkoScan FT2 analysis.

Statistical analysis was carried out by WinISI II (Infrasoft International Inc., State College, PA) through principal component analysis and partial least squares (PLS) regression. A random cross-validation was 
performed by dividing the calibration data set into 5 groups, using 1 group to check the results (prediction) and the remaining 4 groups to construct the calibration model. The model was repeated as many times as there were groups available such that all of them passed through the calibration and prediction set (De Marchi et al., 2013).

Statistical procedures and spectra preprocessing were carried out to improve the accuracy of the calibration models. Outliers samples were selected using the Mahalanobis distance (global $\mathrm{H}>5.0$ ) and samples exceeding 2.5 ( $\mathrm{T}$ outlier value) times the standard error of cross validation $\left(\mathbf{S E}_{\mathbf{C V}}\right)$. Different spectral treatments were compared before PLS analysis to improve spectral information. Spectral corrections were none, standard normal variate $(\mathbf{S N V})$, and standard normal variate + detrending (SNV $+\mathbf{D})$, and mathematical pretreatments (no derivative, first and second derivatives) on different gaps and smoothing segments (from 1 to 10) were performed.

For each WP, the best equation was selected according to standard error of calibration (SEC), coefficient of determination of calibration $\left(\mathrm{R}^{2}\right), \mathrm{SE}_{\mathrm{CV}}$, coefficient of determination of cross-validation $(\mathbf{1}-\mathbf{V R})$, and ratio performance deviation (RPD), calculated as standard deviation/SE $\mathrm{SEV}_{\mathrm{CV}}$. Ratio performance deviation values should be as high as possible: an RPD >10 indicates a method is equivalent to the reference method (Williams and Sobering, 1993) whereas RPD values $>2.5$ indicate a method adequate for analytical purposes (Sinnaeve et al., 1994).

\section{RESULTS}

\section{Separation and Quantification}

Mobile phase composition and wavelength were selected according to a protocol for protein quantification in milk (Bonfatti et al., 2008). Different gradients, flow rates, and temperature conditions were carried out for WP separation using a column made with a superficially thin layer of porous particle. To improve the resolution between peaks, the previous separation conditions were optimized: the selected column temperature and wavelength were $70^{\circ} \mathrm{C}$ and $214 \mathrm{~nm}$, respectively.

The retention time of standard protein solution were used to determine the respective WP fractions in the 187 whey samples. The gradient of mobile phase and flow rate were set to separate in the following order of elution: CMP, PP, $\alpha-\mathrm{LA}, \mathrm{BSA}, \beta-\mathrm{LG}_{\mathrm{B}}$, and $\beta-\mathrm{LG}_{\mathrm{A}}$ (Figure 1). The chromatographic profile of CMP and PP showed several peaks according to the different CMP and PP fractions; thus, a single integration was used and total quantification was calculated for both fractions. The $\alpha$-LA profile reported a double peak related to nonglycosylated and glycosylated fractions, and both

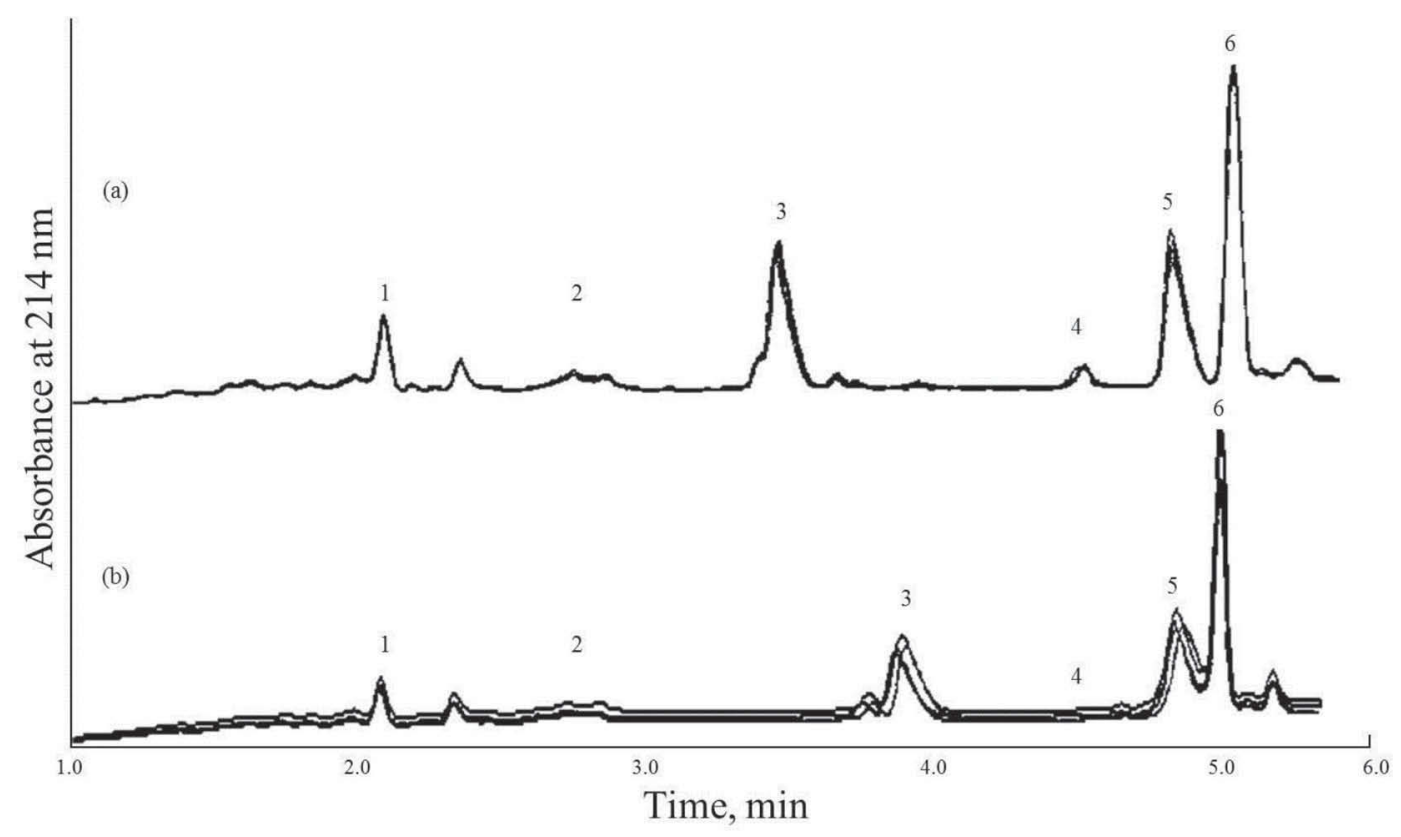

Figure 1. Overlaid chromatograms relative to whey sample in repeatability (a) and reproducibility tests (b) for the whey protein fractions: caseinomacropeptides (CMP; 1), proteose peptones (PP; 2), $\alpha$-LA (3), BSA (4), $\beta$-LG B (5), and $\beta$-LG A (6). 
Table 1. Parameters of regression equations for calibration curves, response factors (RF; $\mu \mathrm{g} /$ area) and limit of detection (LOD) for whey protein fractions by reversed phase-HPLC

\begin{tabular}{|c|c|c|c|c|c|c|}
\hline Protein & $\mathrm{R}^{2}$ & Intercept $\pm \mathrm{SE}$ & Slope & $\begin{array}{l}\mathrm{RF} \pm \mathrm{SD} \\
\times 10^{-3}\end{array}$ & $\begin{array}{c}\mathrm{LOD},{ }^{1} \\
\mu \mathrm{g}\end{array}$ & $\begin{array}{c}\text { Amount } \\
\text { injected, } \mu \mathrm{g}\end{array}$ \\
\hline$\alpha-\mathrm{LA}$ & 0.996 & $66.31 \pm 40.06$ & $1,170.1$ & $0.86 \pm 0.09$ & 0.60 & $3.12-50.0$ \\
\hline BSA & 0.997 & $-4.48 \pm 10.16$ & 809.98 & $1.26 \pm 0.16$ & 0.50 & $1.56-25.0$ \\
\hline Caseinomacropeptides & 0.990 & $0.02 \pm 5.91$ & $1,100.7$ & $0.82 \pm 0.003$ & 0.50 & $1.8-3.6$ \\
\hline Proteose peptone & 0.999 & $-0.02 \pm 4.53$ & $1,001.0$ & $0.96 \pm 0.03$ & 0.50 & $2.5-40.0$ \\
\hline
\end{tabular}

${ }^{1} \mathrm{LOD}=10 \times(3 \times \mathrm{SD})$, where $\mathrm{SD}$ is the standard deviation of the background noise.

peaks were included in the integration for quantitative analysis, because the $\alpha$-LA commercial standard contains both fractions. Bovine serum albumin, $\beta-\mathrm{LG}_{\mathrm{B}}$, and $\beta-\mathrm{LG}_{\mathrm{A}}$ eluted separately in well-defined peaks.

Protein quantification was performed using calibration curves derived from regression parameters computed for the peak area and injected concentration of the single standard pure proteins. Parameters of calibration curve reported for all the protein fractions showed $\mathrm{R}^{2}>$ 0.99 (Table 1). The parameters of regression equations for calibration curves, response factors, and limits of detection for WP fractions are given in Table 1.

\section{Repeatability and Reproducibility Tests}

Repeatability and reproducibility expressed as relative standard deviation (RSD \%) of retention times and peak areas for WP fractions are reported in Table 2. Values of RSD of retention time for repeatability and reproducibility tests showed high precision for each protein fraction both within and between days. For repeatability, the RSD ranged from 0.09 to $0.20 \%$, whereas the RSD for reproducibility ranged from 0.19 to $0.69 \%$. A slight worsening in retention time accuracy was reported between days compared with that within day (Figure 1). Similar results were obtained for peak area, and major accuracy was within day. In repeatabil- ity and reproducibility test for peak area, greater precision was found for those WP present in large amounts in whey: CMP, PP, $\beta-\mathrm{LG}_{\mathrm{A}}$, and $\beta-\mathrm{LG}_{\mathrm{B}}$, with a RSD ranging from 0.55 to $0.79 \%$ and 0.25 to $1.50 \%$ within and between days, respectively. Highest values of RSD for peak area were found for $\alpha$-LA and BSA; indeed, the RSD for repeatability ranged from 2.19 to $2.66 \%$, and that for reproducibility ranged from 3.0 to $2.65 \%$.

\section{Prediction of WP by MIRS}

Prediction models were obtained omitting the portion of MIR spectra from 1,550 to $1,658 \mathrm{~cm}^{-1}$ and from 2,955 to $4,000 \mathrm{~cm}^{-1}$ due to water absorption with low signal-to-noise ratio. Figure 2 depicts an example of whey spectra without the aforementioned noninformative regions.

Numbers of samples selected for the calibration models differed for each WP fraction, according to outliers setting identification for global $\mathrm{H}$ and $\mathrm{T}$ outlier values. Table 3 shows the summarized average composition of samples selected for the PLS analysis; means (SD) for $\alpha-\mathrm{LA}, \beta-\mathrm{LG}, \beta-\mathrm{LG}_{\mathrm{A}}, \beta-\mathrm{LG}_{\mathrm{B}}$, BSA, CMP, PP, and total quantified WP were $0.73(0.11), 4.06(0.86)$, 2.79 (0.63), 1.30 (0.24), 0.14 (0.03), 0.47 (0.14), 0.19 (0.06), and 5.62 (1.14), respectively. The coefficient of variation $(\mathbf{C V})$ was greater in fractions where fewer

Table 2. Repeatability and reproducibility tests expressed as relative standard deviation (RSD \%) of retention times and peak areas for whey protein fractions quantified by reversed phase-HPLC

\begin{tabular}{lccccc}
\hline & \multicolumn{2}{c}{ Repeatability $^{1}$} & & \multicolumn{2}{c}{ Reproducibility $^{2}$} \\
\cline { 2 - 3 } \cline { 5 - 6 } Protein & Retention time & Area & & Retention time & Area \\
\hline$\alpha-\mathrm{LA}$ & 0.09 & 2.19 & & 0.31 & 3.00 \\
$\beta-\mathrm{LG}_{\mathrm{A}}$ & 0.04 & 0.79 & & 0.19 & 1.50 \\
$\beta-\mathrm{LG}_{\mathrm{B}}$ & 0.06 & 0.68 & & 0.61 & 0.54 \\
BSA & 0.20 & 2.66 & & 0.26 & 2.65 \\
Caseinomacropeptides & 0.16 & 0.55 & & 0.27 & 0.25 \\
Proteose peptone & 0.12 & 0.57 & & 0.69 & 0.32 \\
\hline
\end{tabular}

${ }^{1}$ Ten aliquots of the same whey sample were injected consecutively.

${ }^{2} \mathrm{~A}$ sequence of 10 whey samples was injected over $4 \mathrm{~d}$. 


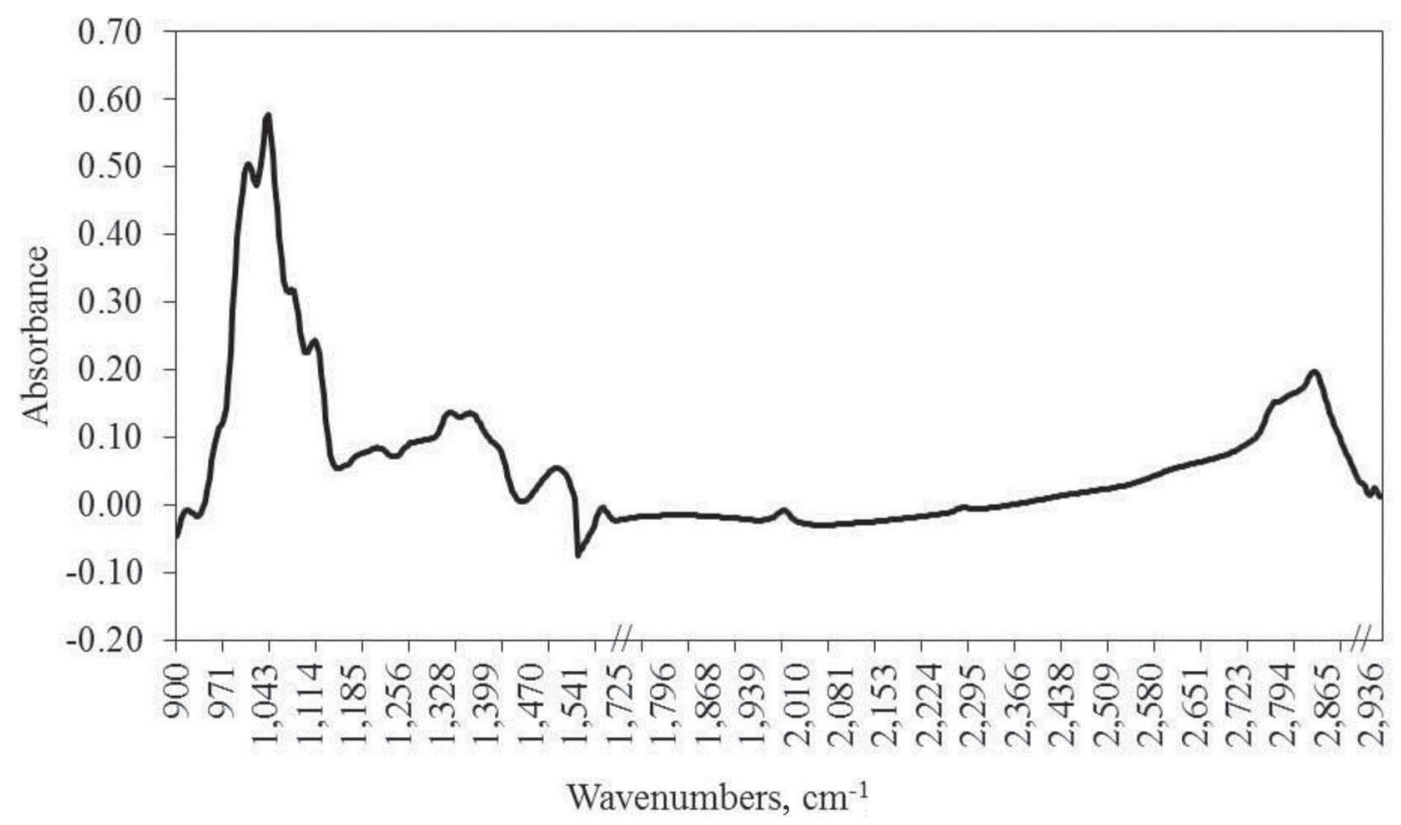

Figure 2. Example of untreated (without scattering correction and no derivative) spectrum with wavenumbers selected for calibration.

samples were discarded as outliers, in particular for CMP (0.29) and PP (0.32) with 181 and 178 samples selected for calibration, respectively, whereas a lower CV was observed for $\alpha$-LA (0.15) in which 18 samples were discarded.

Fitting statistics for MIRS prediction models are shown in Table 4. The number of terms of MIRS prediction models was quite low (ranged from 4 to 9), demonstrating a moderately strong relationship between spectral information and WP fractions. The best prediction models were obtained for WP fractions present in large amounts (i.e., $\beta-\mathrm{LG}$, total identified, $\alpha$-LA). All WP fractions were well predicted by MIRS, with 1 - VR values ranging from $0.50(\mathrm{PP})$ to 0.66 (BSA); only the $\beta-\mathrm{LG}_{\mathrm{B}}$ prediction model showed a poor result $(1-\mathrm{VR}=0.33)$. On average, the differences between calibration $\left(\mathrm{R}^{2}\right)$ and validation $(1-\mathrm{VR})$ statistics were very low, demonstrating the robustness of MIRS models. Scatter plots of predicted versus measured WP are depicted in Figure 3. Ratio performance deviation ranged from $1.22\left(\beta-\mathrm{LG}_{\mathrm{B}}\right)$ to $1.70(\mathrm{BSA})$.

\section{DISCUSSION}

\section{Validation of RP-HPLC Method}

The eluent solution and detection conditions used in the present study were the same as those reported in several studies in whey (Spellman et al., 2005) and in milk (Kiokias et al., 2007). The elution order profile was CMP, PP, $\alpha-L A, B S A, \beta-\mathrm{LG}_{\mathrm{B}}$, and $\beta-\mathrm{LG}_{\mathrm{A}}$. Similar order in retention times was proposed for WPC in the

Table 3. Descriptive statistics of whey protein fractions $(\mathrm{mg} / \mathrm{mL})$ in whey samples selected for the calibration

\begin{tabular}{|c|c|c|c|c|c|}
\hline Protein $^{1}$ & $\begin{array}{c}\text { No. of } \\
\text { samples }^{2}\end{array}$ & Mean & $\mathrm{SD}$ & Minimum & Maximum \\
\hline$\alpha-\mathrm{LA}$ & 169 & 0.73 & 0.11 & 0.43 & 1.01 \\
\hline$\beta-\mathrm{LG}$ & 177 & 4.06 & 0.86 & 1.40 & 6.76 \\
\hline$\beta-\mathrm{LG}_{\mathrm{A}}$ & 177 & 2.79 & 0.63 & 0.65 & 4.72 \\
\hline$\beta-\mathrm{LG}_{\mathrm{B}}$ & 176 & 1.30 & 0.24 & 0.16 & 2.04 \\
\hline BSA & 178 & 0.14 & 0.03 & 0.05 & 0.23 \\
\hline Caseinomacropeptides & 181 & 0.47 & 0.14 & 0.03 & 0.89 \\
\hline Proteose peptone & 178 & 0.19 & 0.06 & 0.01 & 0.33 \\
\hline Total identified & 176 & 5.62 & 1.14 & 1.92 & 9.23 \\
\hline
\end{tabular}

${ }^{1}$ Total $=\alpha-\mathrm{LA}+\beta-\mathrm{LG}+\mathrm{BSA}+$ caseinomacropeptides + proteose peptone.

${ }^{2}$ Number of samples considered to build the equations. 
Table 4. Statistics of prediction models ${ }^{1}$ for whey protein composition $(\mathrm{mg} / \mathrm{mL})$ by mid-infrared spectroscopy $\left(900-4,000 \mathrm{~cm}^{-1}\right)$

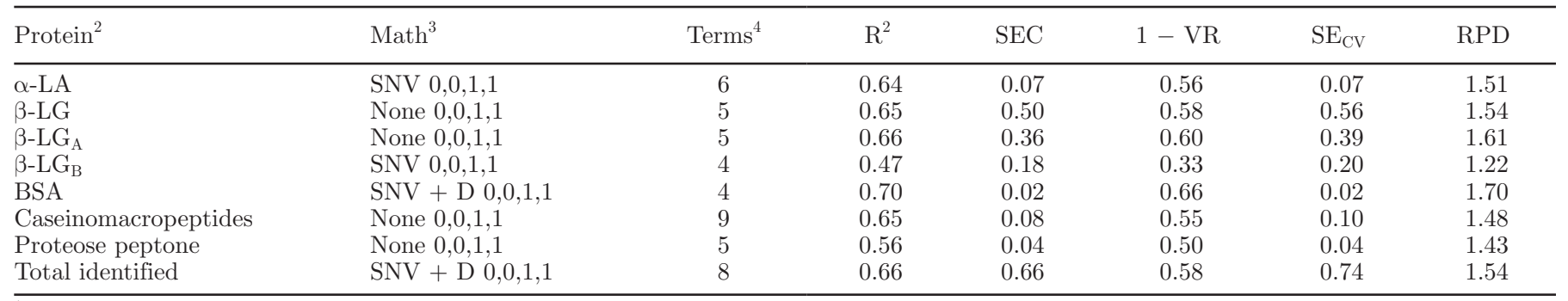

${ }^{1} \mathrm{SEC}=$ standard error of calibration; $1-\mathrm{VR}=$ coefficient of determination of cross-validation; $\mathrm{SE}_{\mathrm{CV}}=$ standard error of cross-validation; $\mathrm{RPD}$ $=$ ratio performance deviation calculated as $\mathrm{SD} / \mathrm{SE}$ CV.

${ }^{2}$ Total $=\alpha-\mathrm{LA}+\beta-\mathrm{LG}+\mathrm{BSA}+$ caseinomacropeptides + proteose peptone.

${ }^{3} \mathrm{SNV}=$ standard normal variate; $\mathrm{D}=$ detrending. The first digit of the mathematical treatment refers to the derivative number $(0=$ no derivative; 1 = first derivative), the second number is the gap over which the derivative is calculated, the third is the length of segment smoothed, and the fourth is the second smoothing segment.

${ }^{4}$ Number of modified partial least squares factors used in calibration.

study of Innocente et al. (2011), which utilized water and $\mathrm{ACN}$ in $0.1 \% \mathrm{TFA}$ as mobile phases. Typical peak positions (protein fingerprints) were reported for CMP variants released in whey by chymosin cleavage of $\kappa$-casein. Indeed, glycosylated and nonglycosylated fractions for both A and B variants were obtained, as reported with the separation proposed by Thomä et al. (2006), using a whey from milk of a single cow homozygous for $\kappa$-casein AA or BB. The selected wavelength $(214 \mathrm{~nm})$ has the advantage of improving sensitivity of response factor for PP fractions, as demonstrated by Elgar et al. (2000) with a column with polystyrene-divinylbenzene matrix. However, a more distinct separation between CMP and PP was obtained using the present column with a thin layer of porous particles that minimizes peak broadening. The $\alpha$-LA elution pattern was in agreement with several studies (Elgar et al., 2000; Thomä et al., 2006), where a partial overlapping of glycated forms was detected. A smaller signal for BSA elution was obtained compared with that reported by Elgar et al. (2000). Moreover, welldefined peaks were reported for both $\beta$-LG variants. The earlier elution of $\beta-\mathrm{LG}_{\mathrm{B}}$ compared with the variant A was also reported in milk (Bobe et al., 1998; Bonfatti et al., 2008) and whey (Elgar et al., 2000). Satisfactory separation between $\beta-\mathrm{LG}_{\mathrm{A}}$ and $\mathrm{B}$ variants was obtained with the present method; previously, Thomä et al. (2006) proposed an acceptable separation profile for $\beta$-LG variants by HPLC, whereas, in other HPLC methods, only a partial separation was commonly reported (Elgar et al., 2000; Innocente et al., 2011).

The temperature selected in this study $\left(70^{\circ} \mathrm{C}\right)$ improved overall WP separation compared with room temperature $\left(25^{\circ} \mathrm{C}\right)$, in agreement with the results of other studies in milk (data not shown; Spellman et al., 2005; Bonfatti et al., 2008).
Variation of RSD values for retention times and peak areas obtained in repeatability and reproducibility tests were similar to those reported in the literature within and across days (Bobe et al., 1998; Bordin et al., 2001; Bonfatti et al., 2008). Our results indicate that repeatability and reproducibility of the method were acceptable, particularly for the most abundant fractions. To improve the accuracy of the method, 2 min of postrun was set to equilibrate the column with the initial condition, for a total run time of 9 min per sample. The present RP-HPLC method was rapid (9 min) and achieved high resolution; therefore, it can be used for WP quantification during whey treatments (e.g., UF).

\section{Prediction of Whey Proteins by MIRS}

In the last $10 \mathrm{yr}$, spectroscopic techniques combined with chemometric analysis have become the preferred method for milk and dairy product analysis. Mid-infrared spectroscopy is one such technique and it is widely used in milk laboratories (De Marchi et al., 2014) for prediction of traditional and new milk quality traits (Soyeurt et al., 2011; Toffanin et al., 2015; Visentin et al., 2015). Different applications of MIRS to predict detailed milk protein compositions have been published (De Marchi et al., 2009; Rutten et al., 2011); nevertheless, the best prediction models were reported by Bonfatti et al. (2011), with $1-$ VR values $>0.53$ for milk protein fractions.

Rapid determination of WP fractions should be a benefit for monitoring WP concentrations during whey filtration treatments. Results from fitting statistics (RPD) suggest that these models might be used for screening and for segregating whey according to WP contents before whey treatment. Indeed, WP composition affects the UF treatment and the resulting product 

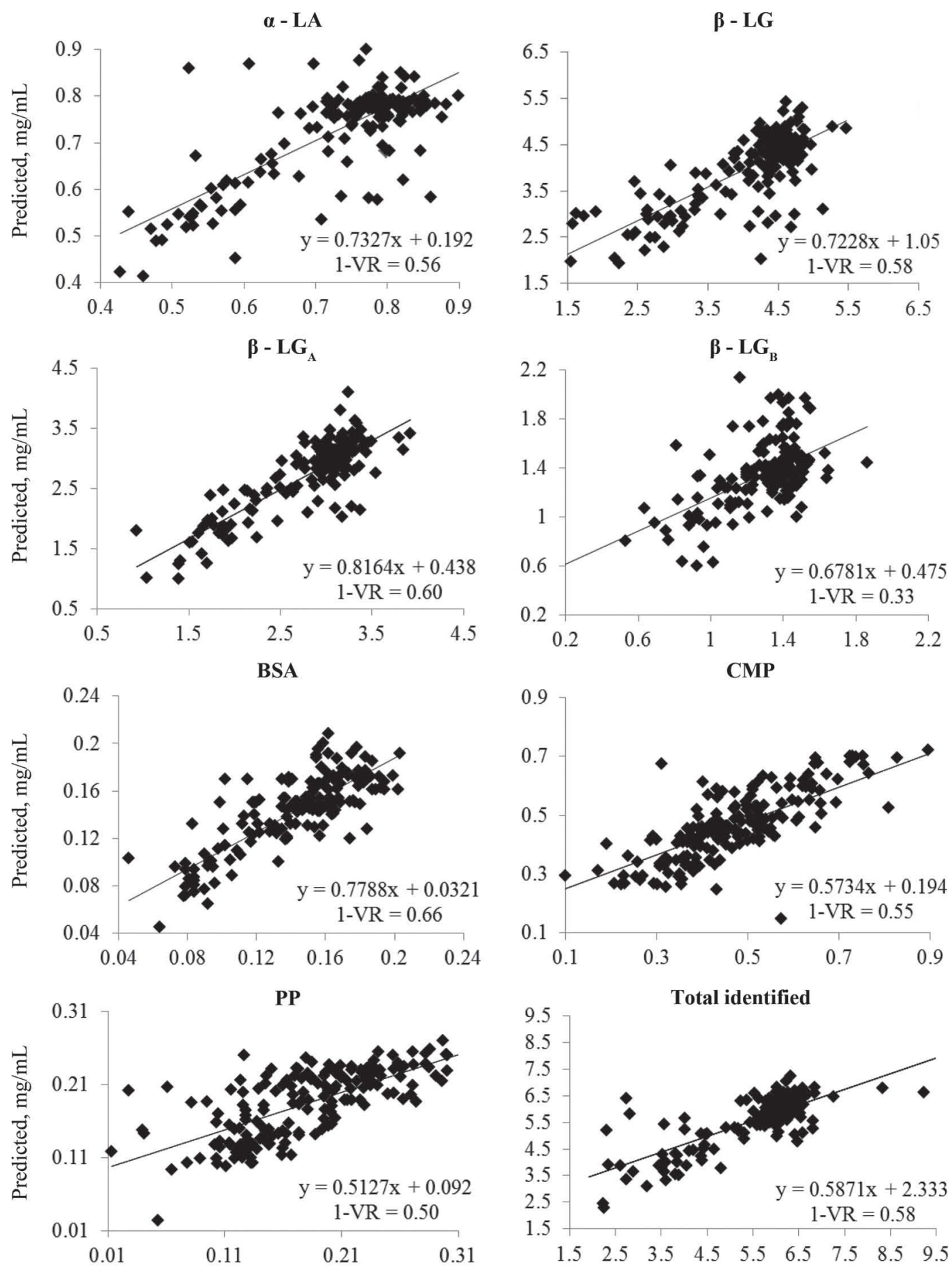

Measured, $\mathrm{mg} / \mathrm{mL}$

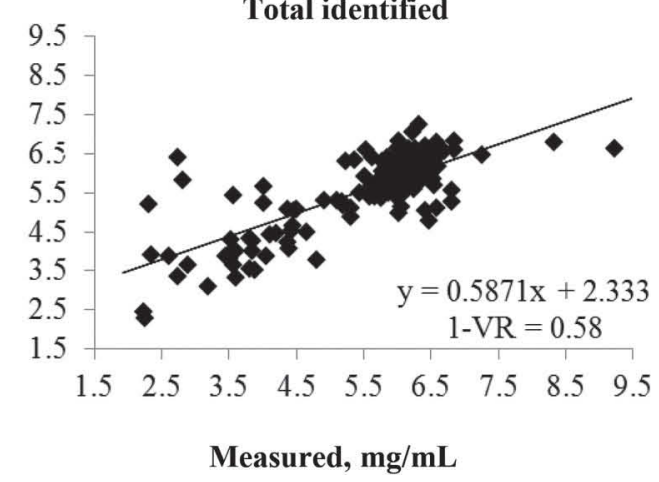

Figure 3. Scatter plot of predicted (y-axis) and measured (x-axis) whey protein fractions (caseinomacropeptides, CMP; proteose peptone, $\mathrm{PP}$; Total $=\alpha-\mathrm{LA}+\beta-\mathrm{LG}+\mathrm{BSA}+\mathrm{CMP}+\mathrm{PP})$, regression equations, and coefficient of determination of cross-validation $(1-\mathrm{VR})$.

(WPC; Guyomarc'h et al., 2009). Products based on WP are used for their emulsifying, fortifying, and nutritive properties. These beneficial effects are related to the major WP ( $\alpha-\mathrm{LA}$ and $\beta-\mathrm{LG}$ ), whereas peptides and minor proteins are neglected during production of WP products. In this regard, MIRS provides a rapid method to classify the optimal whey according to its total and individual WP contents. 
Reference methods play a crucial role in the performance of prediction models and in the selection of spectra pretreatments (De Marchi et al., 2014). The performance of MIRS prediction models for $\alpha-\mathrm{LA}$ and $\beta$-LG in our study was greater than that reported by De Marchi et al. (2009) and Rutten et al. (2011) for whey protein in milk using spectral without scattering correction and no derivative (untreated spectra); nevertheless, in the same untreated spectral condition, Rutten et al. (2011) used a different reference method (electrophoresis) than that used in the present study. Regarding spectral pretreatments, the scientific literature reports contradictory results. Indeed, Bonfatti et al. (2011) reported a greater 1 - VR for $\beta$-LG with several spectral pretreatments, compared with untreated spectra proposed by De Marchi et al. (2009), whereas no difference was reported for $\alpha$-LA in the aforementioned studies, in which the same reference method was used. In the present study, several proteins ( $\beta$-LG, $\beta-\mathrm{LG}_{\mathrm{A}}, \mathrm{CMP}$, and PP) were predicted without spectral pretreatments; indeed, using scatter correction (e.g., SNV), no significant improvement was found compared with the use of untreated spectra. For other WP fractions $\left(\alpha-\mathrm{LA}, \beta-\mathrm{LG}_{\mathrm{B}}\right.$, BSA, and total protein), a scatter correction was required to removed nonlinearities of the spectral data caused by particulates in the samples (Rinnan et al., 2009). Moreover, for all WP, derivatives were not applied, because of the increase in the level of noise that reduces the spectral information.

As reported by De Marchi et al. (2014), protein fractions were better predicted (greater accuracy) when HPLC is used as the reference method compared with capillary zone electrophoresis method, as proposed by Rutten et al. (2011). Moreover, the soluble properties of WP and the greater concentrations of $\alpha-\mathrm{LA}$ and $\beta-\mathrm{LG}$ might explain the better prediction models compared with the other minor WP fractions. As reported by Rutten et al. (2011) in milk, the limited concentration and the micelle status of caseins reduce the prediction ability. The poor ability of spectra to explain variation of $\beta-\mathrm{LG}_{\mathrm{B}}$ was demonstrated by the low values of $1-$ $\mathrm{VR}$ and high $\mathrm{SE}_{\mathrm{CV}}$. Differences in prediction between $\beta-\mathrm{LG}_{\mathrm{A}}$ and $\mathrm{B}$ might be related to the chemical configuration of genetic variants, as reported by Lefèvre and Subirade (2001).

Finally, the prediction models developed in the present study might be used to predict protein contents in raw sweet whey samples. The MIRS prediction models developed in the present study were able to discriminate sweet whey according to WP contents (e.g., high level of $\beta$-LG). Additional MIRS prediction models should be developed to predict WP contents in derived whey products (e.g., WPC) by using the present RP-HPLC method.

\section{CONCLUSIONS}

The recovery of WP from whey and utilization of WP in dairy products is a source of income for dairy industry. This study proposes MIRS model for the prediction of WP composition in sweet whey by using a rapid RP-HPLC method as reference. The reference method was validated by performing repeatability and reproducibility tests. Retention times were stable. Results for area depended on the considered protein and its relative abundance; indeed, the potential of MIRS in predicting WP composition of sweet whey was demonstrated and better MIRS prediction models were obtained for large amounts fractions (i.e., $\beta$-LG, total, $\alpha-\mathrm{LA})$. Even if MIRS has the potential to predict protein composition, better resolution was achieved by RP-HPLC. In conclusion, MIRS is an adequate method for WP prediction in sweet whey and it might be used to screen and classify the optimal whey destined to treatment (e.g., UF) according to its total and individual WP contents.

\section{ACKNOWLEDGMENTS}

The authors thank dairy industry "Latteria di Soligo" (Farra di Soligo, Italy) for financial support and for providing the samples, and Anna Rita Trentin and Micaela Piavato for technical assistance (Department of Agronomy, Food, Natural resources, Animals, and Environment; DAFNAE, University of Padova, Italy). This research was supported by Regione Veneto with the project "Acquadolce" (n 1809089, Misura 124, PSR 2007-2013-DGR n. 745 del 15.03.2010).

\section{REFERENCES}

Anandharamakrishnan, C., C. D. Rielly, and A. G. F. Stapley. 2008. Loss of solubility of $\alpha$-lactalbumin and $\beta$-lactoglobulin during the spray drying of whey proteins. Lebenson. Wiss. Technol. 41:270 277.

Bobe, G., D. C. Beitz, A. E. Freeman, and G. L. Lindberg. 1998. Sample preparation affects separation of whey proteins by reversedphase high-performance liquid chromatography. J. Agric. Food Chem. 46:458-463.

Bonfatti, V., G. Di Martino, and P. Carnier. 2011. Effectiveness of mid-infrared spectroscopy for the prediction of detailed protein composition and contents of protein genetic variants of individual milk of Simmental cows. J. Dairy Sci. 94:5776-5785.

Bonfatti, V., L. Grigoletto, A. Cecchinato, L. Gallo, and P. Carnier. 2008. Validation of a new reversed-phase high-performance liquid chromatography method for separation and quantification of bovine milk protein genetic variants. J. Chromatogr. A 1195:101-106.

Bordin, G., F. C. Raposo, B. de la Calle, and A. R. Rodriguez. 2001. Identification and quantification of major bovine milk proteins by liquid chromatography. J. Chromatogr. A 928:63-76.

De Marchi, M., V. Bonfatti, A. Cecchinato, G. Di Martino, and P. Carnier. 2009. Prediction of protein composition of individual cow milk using mid-infrared spectroscopy. Ital. J. Anim. Sci. 8(Suppl. 2):399-401. 
De Marchi, M., V. Toffanin, M. Cassandro, and M. Penasa. 2013. Prediction of coagulating and noncoagulating milk samples using mid-infrared spectroscopy. J. Dairy Sci. 96:4707-4715.

De Marchi, M., V. Toffanin, M. Cassandro, and M. Penasa. 2014. Invited review: Mid-infrared spectroscopy as phenotyping tool for milk traits. J. Dairy Sci. 97:1171-1186.

Dissanayake, M., and T. Vasiljevic. 2009. Functional properties of whey proteins affected by heat treatment and hydrodynamic highpressure shearing. J. Dairy Sci. 92:1387-1397.

Doultani, S., K. N. Turhan, and M. R. Etzel. 2004. Fractionation of proteins from whey using cation exchange chromatography. Process Biochem. 39:1737-1743.

Elgar, D. F., C. S. Norris, J. S. Ayers, M. Pritchard, D. E. Otter, and K. P. Palmano. 2000. Simultaneous separation and quantitation of the major bovine whey proteins including proteose peptone and caseinomacropeptide by reversed-phase high-performance liquid chromatography on polystyrene-divinylbenzene. J. Chromatogr. A 878:183-196.

Guyomarc'h, F., M. Nono, T. Nicolai, and D. Durand. 2009. Heatinduced aggregation of whey proteins in the presence of k-casein or sodium caseinate. Food Hydrocoll. 23:1103-1110.

Innocente, N., M. Biasutti, and C. Blecker. 2011. HPLC profile and dynamic surface properties of the proteose-peptone fraction from bovine milk and from whey protein concentrate. Int. Dairy J. $21: 222-228$.

Kiokias, S., C. Dimakou, and V. Oreopoulou. 2007. Effect of heat treatment and droplet size on the oxidative stability of whey protein emulsions. Food Chem. 105:94-100.

Lefèvre, T., and M. Subirade. 2001. Molecular structure and interaction of biopolymers as viewed by Fourier transform infrared spectroscopy: model studies on $\beta$-lactoglobulin. Food Hydrocoll. 15:365-376.

Lo, C. G., and E. D. Bastian. 1998. Incorporation of native and denatured whey proteins into cheese curd for manufacture of reduced fat, Havarti-type cheese. J. Dairy Sci. 81:16-24.

Mollè, D., K. Jean, and F. Guyomarc'h. 2006. Chymosin sensitivity of heat-induced serum protein aggregated isolated from skim milk. Int. Dairy J. 16:1435-1441.

Paquet, D., Y. Nejjar, and G. Linden. 1988. Study of hydrophobic protein fraction isolated from milk proteose-peptone. J. Dairy Sci. $71: 1464-1471$.

Prazeres, A. R., F. Carvalho, and J. Rivas. 2012. Cheese whey management: A review. J. Environ. Manage. 110:48-68.
Rinnan, A., L. Norgaard, F. van den Berg, J. Thygesen, R. Bro, and S. B. Engelsen. 2009. Data pre-processing. Chapter 2 in Infrared Spectroscopy for Food Quality Analysis and Control. Academic Press, London, UK.

Rutten, M. J. M., H. Bovenhuis, J. M. L. Heck, and J. A. M. van Arendonk. 2011. Predicting bovine milk protein composition based on Fourier transform infrared spectra. J. Dairy Sci. 94:5683-5690.

Singer, N. S., S. Yamamoto, and J. Latella. 1990. Protein product base. Jmh Partners Corp., assignee. US Pat. No. 4734287A.

Sinnaeve, G., P. Dardenne, R. Agneessens, and R. Biston. 1994. The use of near infrared spectroscopy for the analysis of fresh grass silage. J. Near Infrared Spectrosc. 2(Spec.):79-84.

Smithers, G. 2008. Whey and whey proteins-From 'gutter-to-gold'. Int. Dairy J. 18:695-704.

Soyeurt, H., F. Dehareng, N. Gengler, S. McParland, E. Wall, D. P. Berry, M. Coffey, and P. Dardenne. 2011. Mid-infrared prediction of bovine milk fatty acids across multiple breeds, production system, and countries. J. Dairy Sci. 94:1657-1667.

Spellman, D., G. O'Cuinn, and R. J. FitzGerald. 2005. Physicochemical and sensory characteristics of whey protein hydrolysates generated at different total solids levels. J. Dairy Res. 72:138-143.

Thomä, C., I. Krause, and U. Kulozik. 2006. Precipitation behaviour of caseinomacropeptides and their simultaneous determination with whey proteins by RP-HPLC. Int. Dairy J. 16:285-293.

Toffanin, V., M. De Marchi, N. Lopez-Villalobos, and M. Cassandro, 2015. Effectiveness of mid-infrared spectroscopy for prediction of the contents of calcium and phosphorus, and titratable acidity of milk and their relationship with milk quality and coagulation properties. Int. Dairy J. 41:68-73.

Torres, I. C., T. Janhøj, B. Ø. Mikkelsen, and R. Ipsen. 2011. Effect of microparticulated whey protein with varying content of denatured protein on the rheological and sensory characteristics of low-fat yoghurt. Int. Dairy J. 21:645-655.

Visentin, G., A. McDermott, S. McParland, D. P. Berry, O. A. Kenny, A. Brodkorb, M. A. Fenelon, and M. De Marchi. 2015. Prediction of bovine milk technological traits from mid-infrared spectroscopy analysis in dairy cows. J. Dairy Sci. 98:6620-6629.

Williams, P. C., and D. C. Sobering. 1993. Comparison of commercial near infrared transmittance and reflectance instruments for analysis of whole grains and seeds. J. Near Infrared Spectrosc. 1(Spec.):25-32. 